\title{
Gene polymorphisms in ULK1 and PIK3CA are associated with the risk of microscopic polyangiitis in the Guangxi Zhuang Autonomous Region in China
}

\author{
Yan Zhu ${ }^{1,2}$, Jinlan Rao ${ }^{1}$, jingsi Wei ${ }^{1}$, Liu Liu ${ }^{1}$, Shanshan Huang ${ }^{1}$, Jingjing Lan ${ }^{1}$, Chao Xue ${ }^{\text {Corresp., } 1}{ }^{1}$, Wei Li ${ }^{\text {Corresp. } 1}$ \\ ${ }^{1}$ The Second Affiliated Hospital of Guangxi Medical University, Department of Nephrology, Nanning, Guangxi, 53000, China \\ 2 The First Affiliated Hospital, Department of Nephrology, Hengyang Medical School, University of South China, Hengyang, Hunan, 421001, China \\ Corresponding Authors: Chao Xue, Wei Li \\ Email address: xccqh@126.com, liwei030514@126.com
}

Background. Microscopic polyangiitis (MPA) is a systemic autoimmune disease characterized by inflammation of small- and medium-sized blood vessels. Autophagy-related protein polymorphisms are involved in autoimmune disease. The aim of this study was to evaluate the effects of single-nucleotide polymorphisms (SNPS) in the ULK1 and PIK3CA genes on the risk of MPA.

Method: A total of 208 patients with MPA and 211 controls in the Guangxi Zhuang Autonomous Region were recruited and analyzed. The SNPs selected were detected by polymerase chain reaction and highthroughput sequencing. The differences in allele and genotype frequency, various genetic models, and stratification analyses were evaluated, haplotype evaluation was performed after linkage disequilibrium analysis, and the interaction between gene alleles was analyzed.

Result: A statistically significant difference was detected in the genotypic distribution of two SNPS between the two groups: ULK1 rs4964879 ( $p=0.019)$ and PIK3CA rs1607237 ( $p=0.002)$. The results of the genetic models revealed that ULK1 rs4964879 and rs9481 are statistically significantly associated with an increased risk of MPA, whereas PIK3CA rs1607237 is associated with a reduced risk. The association between SNPS and MPA risk is affected by age, sex, and ethnicity. The ULK1 haplotype (G-TA-C-G-A) and PIK3CA haplotype (T-G) are associated with a reduced risk of MPA, while the PIK3CA haplotype (C-G) is associated with an increased risk.

Conclusion: In this study, polymorphisms in the autophagy-related genes ULK1 and PIK3CA and their association with MPA were examined. The results showed that the polymorphisms in ULK1 (rs4964879 and rs9481) and PIK3CA (rs1607237) were significantly associated with MPA risk in the Guangxi population. However, the molecular mechanisms are still unclear; basic science research and studies with larger samples are needed to confirm our conclusions and explore the underlying mechanisms. 


\section{Gene polymorphisms in $U L K 1$ and $P I K 3 C A$ are associated}

2 with the risk of microscopic polyangiitis in the Guangxi

3 Zhuang Autonomous Region in China

4

5 Yan Zhu ${ }^{1,2}$, Jinlan Rao ${ }^{1}$, Jingsi Wei ${ }^{1}$, Liu Liu ${ }^{1}$, Shanshan Huang ${ }^{1}$, Jingjing Lan ${ }^{1}$, Chao Xue ${ }^{1}$, Wei Li ${ }^{1}$.

6

$7{ }^{1}$ The Second Affiliated Hospital of Guangxi Medical University, Department of Nephrology, Nanning,

8 Guangxi, 53000, China

$9{ }^{2}$ The First Affiliated Hospital, Department of Nephrology, Hengyang Medical School, University of

10 South China, Hengyang, Hunan, 421001, China

11

12

Corresponding Author:

Chao Xue, Email address: xccqh@126.com;

14 Wei Li, Email address: liwei030514@126.com.

15

16

17

18

19

20

21

22

23

24

25

26

27

28

29

30

31

32

33

34

35

36 
37 Abstract

38 Background. Microscopic polyangiitis (MPA) is a systemic autoimmune disease characterized by

39 inflammation of small- and medium-sized blood vessels. Autophagy-related protein polymorphisms are

40 involved in autoimmune disease. The aim of this study was to evaluate the effects of single-nucleotide

41 polymorphisms (SNPs) in the ULK1 and PIK3CA genes on the risk of MPA.

42 Method: A total of 208 patients with MPA and 211 controls in the Guangxi Zhuang Autonomous Region

43 were recruited and analyzed. The SNPs selected were detected by polymerase chain reaction and high-

44 throughput sequencing. The differences in allele and genotype frequency, various genetic models, and

45 stratification analyses were evaluated, haplotype evaluation was performed after linkage disequilibrium

46 analysis, and the interaction between gene alleles was analyzed.

47 Result: A statistically significant difference was detected in the genotypic distribution of two SNPs

48 between the two groups: ULK1 rs4964879 $(p=0.019)$ and PIK3CA rs1607237 ( $p=0.002)$. The results of

49 the genetic models revealed that $U L K 1$ rs4964879 and rs9481 are statistically significantly associated

50 with an increased risk of MPA, whereas PIK3CA rs1607237 is associated with a reduced risk. The

51 association between SNPs and MPA risk is affected by age, sex, and ethnicity. The ULK1 haplotype (G-

52 T-A-C-G-A) and PIK3CA haplotype (T-G) are associated with a reduced risk of MPA, while the PIK3CA

53 haplotype (C-G) is associated with an increased risk.

54 Conclusion: In this study, polymorphisms in the autophagy-related genes ULK1 and PIK3CA and their

55 association with MPA were examined. The results showed that the polymorphisms in ULK1 (rs4964879

56 and rs9481) and PIK3CA (rs1607237) were significantly associated with MPA risk in the Guangxi

57 population. However, the molecular mechanisms are still unclear; basic science research and studies with

58

59

60

61

\section{Introduction}

62

63

Antineutrophil cytoplasmic antibody (ANCA)-associated vasculitis (AAV) is a group of autoimmune diseases characterized by the inflammation of small- and medium-sized blood vessels. AAV is divided into granulomatosis with polyangiitis (GPA), microscopic polyangiitis (MPA), and eosinophilic GPA (EGPA). Each clinical phenotype is associated with the presence of circulating ANCAs, mainly proteinase-3 (PR3) and myeloperoxidase (MPO) (Ramponi et al. 2021). AAV is more common in males than females, and its incidence rate increases with age, especially in the range of 60-70 years (Geetha \& Jefferson 2020). Additionally, a notable geographic preponderance of MPA rather than GPA and EGPA is observed in China (Chang et al. 2019).

The precise mechanism of AAV remains unestablished, but a genome-wide association study (GWAS) identified the genetic component in the development of this autoimmune disease. A GWAS conducted in a North American cohort demonstrated that GPA is significantly associated with singlenucleotide polymorphisms (SNPs) in the HLA region encoding major histocompatibility complex (MHC) Class II (Xie et al. 2013). A European study showed that the genetic association with AAV is antigen specificity. PR3-ANCA is associated with HLA-DP, which encodes SERPINA1 and PRTN3, while MPO-ANCA is associated with HLA-DQ (Lyons et al. 2012). Consistent with previous studies, a new large GWAS revealed that MHC and non-MHC gene variates are related to GPA/MPA susceptibility, and changing the expression of genes and proteins is associated with the immune response (Merkel et al. 2017). 
80

81

82

83

84

85

86

87

88

89

90

91

92

93

94

95

96

97

98

99

100

101

102

103

104

105

106

107

108

109

110

111

112

113

114

115

116

117

118

119

120

121

122

123

Autophagy is an essential metabolic process in eukaryotic cells, and autophagy-related proteins are involved in various pathologies, including disorders of immune regulation, inflammation, and cancer $(\mathrm{Wu}$ \& Adamopoulos 2017). The PI3K/AKT/mTOR/ULK1 signaling pathway is one of the main regulators of autophagy. Uncoordinated 51-like kinase 1 (ULK1) is a serine/threonine kinase that plays a key role in the formation of the ULK1 complex. The human ULK1 complex can induce the initiation of the autophagy pathway and maturation of autophagosomes (Lin \& Hurley 2016). PIK3CA encodes the p110 $\alpha$ catalytic subunit of phosphatidylinositol 3-kinase (PI3K), which can inactivate mTOR through the PIK3CA/AKT signaling pathway and lead to autophagy (Qu et al. 2016). PIK3CA and ULK1 are the core components of this signaling pathway, and their mutations may alter the autophagy response and cause a change in the incidence of disease risk (Morgan et al. 2012; Qu et al. 2016; Zhang \& Zhou 2019; Zhang et al. 2017).

Numerous studies have revealed that autoimmune diseases may share susceptibility genes. ULK1 has been shown to be associated with ankylosing spondylitis (Zhang et al. 2017) and Crohn's disease (Morgan et al. 2012). The cooccurrence of systemic lupus erythematosus (SLE) and AAV reported in cases suggests that these two diseases may have shared genetic factors, especially in MPO-ANCApositive AAV (Hervier et al. 2012). Emerging evidence shows that autophagy-related gene polymorphisms, such as mTOR (Saravani et al. 2020) and ATG5 (López et al. 2013), participate in SLE. However, as an autoimmune disease, the role of autophagy-related gene mutations in AAV has not yet been reported. Considering that MPA is the most common clinical subtype of AAV in China, we focused on whether gene polymorphisms of ULK1 and PIK3CA play a role in susceptibility to MPA. In the present study, SNP loci with a minor allele frequency (MAF) $\geq 5 \%$ in the functional region of the ULKI and PIK3CA genes were selected, and the association between these two gene polymorphisms and susceptibility to MPA was explored in a group of patients with MPA and a healthy control group from the Guangxi Zhuang Autonomous Region in China.

\section{Materials \& Methods}

\section{Study population}

A total of 208 eligible patients with MPA were recruited from September 2009 to April 2020 in the Department of Nephrology of the Second Affiliated Hospital of Guangxi Medical University (formerly Western Hospital of the First Affiliated Hospital of Guangxi Medical University). The inclusion criteria were as follows: (i) all cases were classified and evaluated as MPA according to the 2012 Revised International Chapel Hill Consensus Conference Nomenclature of Vasculitis (Jennette et al. 2013), (ii) age $\geq 18$ years, and (iii) all patients were born in the Guangxi Zhuang Autonomous Region and had no blood relationship. Patients with secondary vasculitis, other autoimmune diseases, chronic disease and malignant tumors were excluded. A total of 211 healthy volunteers matching the MPA group with respect to age and sex were enrolled as the control group.

The basic clinical information of the patients with MPA and the healthy controls is presented in Table 1. The age range at presentation was $18-82$ years, with a mean age of $54.6 \pm 14.9$ years, of which 114 cases were $<60$ years, and $62.5 \%$ were female. The MPA group had 131 Han and 75 Zhuang nationality populations. The mean BVAS at diagnosis was $16.8 \pm 4.43$. In this study, 36 biopsy specimens (40.4\%) were classified as focal, $9(10.1 \%)$ as crescentic, $20(22.5 \%)$ as mixed, and $24(27 \%)$ as sclerotic. Tubulointerstitial injury was graded as follows: $37(41.6 \%)$ had a score of 1, $41(46.1 \%)$ had a score of 2 , and $11(12.4 \%)$ had a score of 3 . The control group (mean age $51.2 \pm 12.6$ years) consisted of 128 females and 155 Han nationality populations. This study was approved by the Ethics Committee of the Second

Peer) reviewing PDF | (2021:06:62693:2:0:NEW 30 Sep 2021) 
124

125

126

127

128

129

130

131

132

133

134

135

136

137

138

139

140

141

142

143

144

145

146

147

148

149

150

151

152

153

154

155

156

157

158

159

160

161

162

163

164

165

166

Affiliated Hospital of Guangxi Medical University (No. 2018 KY-0100) and followed the principles of the Helsinki Declaration. Written informed consent was obtained from all participants.

\section{DNA isolation}

Blood $(5 \mathrm{ml})$ was collected from the ulnar vein of each participant. Total genomic DNA was extracted from peripheral blood samples using a blood DNA extraction kit (Tiangen, Beijing, China) according to the manufacturer's instructions, and the quality was checked by a Nanodrop 2000 spectrophotometer (Thermo Scientific). Samples with an A260/A280 ratio of 1.7-1.9 were included in the study, and the isolated DNA was stored at $-80^{\circ} \mathrm{C}$ for further studies.

\section{Tag SNP selection}

Six SNPs of the ULK1 gene (rs10902469, rs12303764, rs4964879, rs7300908, rs7138581 and rs9481) and two SNPs of the PIK3CA gene (rs1607237 and rs9838117) were selected from genotype data of Chinese people in the 1000 Genomes (http://grch37.ensembl.org/). The selection criteria included the following: 1) sites located in the functional region, 2) previously reported associations with autoimmune or inflammatory diseases, 3) select tag SNPs as determined using HaploReg, and 4) MAF $\geq 0.05$.

\section{SNP genotyping assay}

SNPs of the ULK1 and PIK3CA genes were detected by polymerase chain reaction (PCR) and highthroughput sequencing (Sangon Biotech, Shanghai, China). The PCR amplification conditions were settled by the two-step method. HiSeq XTen sequencers (Illumina, San Diego, CA, USA) were used to perform paired-end sequencing of the library, and the data were analyzed using Samtools 0.1.18 software. Approximately $10 \%$ of the randomly selected samples were sequenced by Sangon Biotechnology Company (Shanghai, China) to verify the accuracy of genotyping, and the reproducibility rate of all SNP genotyping was $100 \%$.

\section{Statistical analysis}

The genotypic and allelic frequencies in the MPA group and the control group were evaluated by the chi-square test or Fisher's exact test. Hardy-Weinberg equilibrium (HWE) in the control participants was tested using the chi-square test for each SNP. Genetic models and stratification analyses with odds ratios (ORs) and 95\% confidence intervals (CIs) were analyzed to estimate the relationship between genetic variation and the risk of MPA through online SNPstats software (https://www.snpstats.net/start.htm) adjusted by age and sex. Pairwise linkage disequilibrium (LD) and haplotype blocks as measured by D' were evaluated by online software (SHEsis) ((Shi \& He 2005). The interactions between SNPs of the ULK1 gene and PIK3CA gene were evaluated using generalized multifactor dimensionality reduction (GMDR). SPSS Statistics version 23.0 (IBM, Armonk, NY, USA) was used to analyze the data, and $p<0.05$ was considered statistically significant.

\section{Results}

\section{Association of gene polymorphisms with MPA susceptibility}

The genotyping results for quality control ranged from $97.18 \%$ to $99.76 \%$. Detailed information on all SNPs is provided in Table 2 (SNP IDs, locations and allele frequencies). In the selected SNPs, all ANPs had a MAF of $>5 \%$, and the genotype distribution in the control group was in HWE $(p>0.05)$.

Peer] reviewing PDF | (2021:06:62693:2:0:NEW 30 Sep 2021) 
167

168

169

170

171

172

173

174

175

176

177

178

179

180

181

182

183

184

185

186

187

188

189

190

191

192

193

194

195

196

197

198

199

200

201

202

203

204

205

206

207

208

209

According to the single-SNP analyses, the allele frequencies of PIK3CA rs1607237 (C>T) were significantly different between the MPA group and the control group $(p=0.011)$.

The association between the SNPs and the risk of MPA was identified by genetic models (codominant, dominant, recessive, and overdominant) and genotype frequencies (Table 3). The results adjusted by age and sex showed that rs4964879 in the $U L K 1$ gene significantly increased the risk of MPA with the GA genotype in the codominant model (GA versus AA, OR $=1.76,95 \% \mathrm{CI}: 1.15-2.70$, and $p=$ 0.03 ), the dominant model (GA/GG versus $\mathrm{AA}, \mathrm{OR}=1.60,95 \% \mathrm{CI}: 1.07-2.40$, and $p=0.022$ ) and overdominant model (GA versus $\mathrm{AA} / \mathrm{GG}, \mathrm{OR}=1.68,95 \% \mathrm{CI}: 1.13-2.49$, and $p=0.0096$ ). The risk of MPA in the $U L K 1$ gene rs 9481 was 1.77 times that in healthy controls in the recessive model (GG versus AA/AG, 95\% CI: 1.06-2.94, and $p=0.027$ ). The mutations of rs1607237 in the PIK3CA gene had a lower incidence of MPA with the CT genotype in the codominant model (CT versus $\mathrm{CC}, \mathrm{OR}=0.47,95 \%$ CI: $0.30-0.73$, and $p=0.0039)$, the dominant model (CT/TT versus CC, OR $=0.55,95 \%$ CI: $0.37-0.82$, and $p=0.0031$ ), and the overdominant model (CT versus CC/TT, OR $=0.49,95 \% \mathrm{CI}: 0.32-0.76$, and $p=$ $0.0013)$. No significant difference was observed for the other gene loci between the cases and controls $(p$ $>0.05)$.

\section{Linkage disequilibrium analysis}

Figure 1 shows the pattern of pairwise LD with respect to the analyzed SNPs of two genes in the current study. The LD plot indicated that the ULK1 rs10902469, rs12303764, rs4964879, rs7300908, rs7138581, and rs9481 loci formed six haplotypes (Table 4). Haplotype G-T-A-C-G-A was the most commonly observed haplotype in the cases $(49.2 \%)$ and in the healthy controls $(56.1 \%)$ and was associated with a reduced risk of MPA (OR $=0.749,95 \% \mathrm{CI}: 0.563-0.997, p=0.047)$. Other haplotypes did not exhibit an association with MPA. The SNP loci of the PIK3CA genes rs1607237 and rs9838117 also formed three haplotypes (Table 4). The results showed that the C-G haplotype was the most commonly observed haplotype in the cases $(73.3 \%)$ and in the healthy controls $(66.7 \%)$ and was associated with an increased risk of MPA (OR $=1.427,95 \% \mathrm{CI}: 1.050-1.939$, and $p=0.023)$. The T-G haplotype was significantly associated with a reduced risk of MPA (OR $=0.520,95 \%$ CI: $0.339-0.799$, and $p=0.0025)$.

\section{Stratification analysis based on age, sex and ethnicity}

The analysis results showed that age, sex, and ethnicity significantly affected the association between ULK1 and PIK3CA SNPs and MPA risk. The mutations of ULK1 rs4964879 (with GA genotype in the overdominant model, $\mathrm{OR}=1.65,95 \% \mathrm{CI}: 1.01-2.69$, and $p=0.046$ ) and rs9481 (with GG genotype in the recessive model, $\mathrm{OR}=1.88,95 \% \mathrm{CI}: 1.01-3.51$, and $p=0.047$ ) were associated with a higher incidence of MPA in the population aged $<60$ years; PIK3CA rs1607237 was associated with a decreased MPA risk under the codominant model ( $\mathrm{CT}$ versus $\mathrm{CC}, \mathrm{OR}=0.23,95 \% \mathrm{CI}: 0.10-0.53$, and $p$ $<0.001$ ), the dominant model (CT/TT versus $\mathrm{CC}$, OR $=0.41,95 \% \mathrm{CI}: 0.20-0.85$, and $p=0.016$ ), and the overdominant model (CT versus CC/TT, OR $=0.21,95 \% \mathrm{CI}: 0.09-0.49$, and $p<0.001$ ) in the population $\geqq 60$ years (Table 5 ). The results were adjusted by sex.

The results also showed that sex significantly affected the association between SNPs and MPA risk (Table 6). ULK1 rs4964879 in females under the dominant model (GA/GG versus AA, OR $=1.69,95 \%$ CI: $1.02-2.82$, and $p=0.042$ ) and the overdominant model (GA versus $\mathrm{AA} / \mathrm{GG}, \mathrm{OR}=1.74,95 \% \mathrm{CI}$ : $1.05-2.88$, and $p=0.031$ ), which could increase MPA risk. Marginal evidence revealed that rs9481 in 
210 females under the regressive model increased MPA risk $(p=0.05)$. PIK3CA rs1607237 was associated

211 with a decreased MPA risk in the population, independent of sex. The results were adjusted by age.

212 In addition, the results showed that the Han population with the ULK1 rs4964879 mutation had a 213 higher incidence of MPA with the GA genotype under the dominant model (GA/GG versus AA, OR = $2141.78,95 \%$ CI: 1.09-2.90, and $p=0.02$, Table 7) and the overdominant model (GA versus AA/GG, OR = $2151.70,95 \%$ CI, 1.05-2.74, and $p=0.03$ ); the Han population with PIK3CA rs1607237 could significantly 216 decrease MPA risk with the CT genotype in the codominant model (CT versus CC, OR $=0.42,95 \%$ CI: $2170.24-0.73$, and $p=0.0068)$, the dominant model (CT/TT versus CC, OR $=0.48,95 \% \mathrm{CI}: 0.29-0.78$, and $218 p=0.0031$ ) and the overdominant model (CT versus CC/TT, OR $=0.44,95 \% \mathrm{CI}: 0.26-0.76, p=0.0026$ ). 219 The results were adjusted by sex and age.

220

221

222

223

224

225

226

227

228

229

230

231

232

233

234

235

236

237

238

239

240

241

242

243

244

245

246

247

248

249

250

251

252

\section{Interaction of gene alleles with clinical characteristics}

Generalized multifactor dimensionality reduction (GMDR) was used to analyze the interaction between the alleles of the $U L K 1$ gene (rs10902469, rs12303764, rs4964879, rs7300908, rs7138581, and rs9481) and PIK3CA gene (rs1607237 and rs9838117). The interaction showed that rs4964879 and rs1607237 were the best models for MPA prediction (cross-validation consistency: 10/10). The risk of MPA in the "high-risk" combination was 2.27 times that in the "low-risk combination" (Figure 2), but a margin testing $p$ value was observed $(p=0.0547)$.

\section{Discussion}

In this study, polymorphisms in the autophagy-related genes ULK1 and PIK3CA and their association with MPA were examined. The results showed that the ULK1 SNPs rs4964879 and rs9481 were risk factors for MPA, and PIK3CA rs1607237 was a protective factor for MPA.

Autophagy is a fundamental intracellular biological process of eukaryotic cells that is essential for the activation of innate and adaptive immune responses, including self-antigen presentation, phagocytosis, maintenance of lymphocyte homeostasis, and regulation of cytokine production (Ye et al. 2019). It is well established that the mammalian target of rapamycin (mTOR)/ULK1 pathway is one of the main regulators of autophagy. Inhibition of mTOR results in dephosphorylation of ULK1 and upregulates autophagy, and it is positively modulated through the PI3K/AKT pathway and negatively modulated by adenosine monophosphate-activated protein kinase (Mohamed et al. 2021). Increasing studies have demonstrated that autophagy is involved in the biology of neutrophils, which play a critical role in the acute injury of AAV by releasing proteolytic enzymes via degranulation, producing reactive oxygen species and extruding neutrophil extracellular traps (NETs) (Al-Hussain et al. 2017; Skendros et al. 2018). Li-Li Sha et al. proved that autophagy activity is elevated in neutrophils treated with ANCAs, and the NET formation rate increases or decreases in neutrophils pretreated with an autophagy inducer or inhibitor, respectively (Sha et al. 2016). Sha Tang et al. also demonstrated that NET formation is associated with autophagy-related signaling in human neutrophils with AAV (Tang et al. 2015).

In this study, six SNPs (rs10902469, rs12303764, rs4964879, rs7300908, rs7138581, and rs9481) in ULK1 between healthy controls and MPA patients were evaluated. Our initial single SNP analysis detected a significant difference in the genotypic distribution (rs4964879, A > G) between the two groups. Subsequently, rs4964879 (codominant, dominant and overdominant model) and rs9481 (recessive model) of the ULK1 gene were significantly associated with the risk of MPA. In addition, the association between $U L K 1$ gene polymorphisms and MPA risk was influenced by age, sex and ethnicity. Our findings

Peer] reviewing PDF | (2021:06:62693:2:0:NEW 30 Sep 2021) 
indicated that rs4964879 and rs9481 variations $(\mathrm{A}>\mathrm{G})$ in the $U L K 1$ gene may be able to increase susceptibility to MPA.

$U L K 1$, which is a serine/threonine protein kinase, plays a central role in initiating autophagy. It has been reported that the knockdown of ULK1 in HEK293 cells is sufficient to inhibit the autophagy response (Chan et al. 2007). Mouse embryonic fibroblasts derived from ULK1/- and ULK2-- mice blocked autophagy during amino acid starvation (Cheong et al. 2011). As expected by the role of ULK1 kinase in autophagy initiation, genetic variation in ULKI could result in autophagy disorder. David J. Horne et al. found that ULK1-deficient cells present decreased cytokine secretion and autophagy activity. The study was also the first to report that the rs12297124 minor allele of the ULK1 gene contributes to an $80 \%$ reduction in latent tuberculosis infection risk in Asian participants (Horne et al. 2016). The ULK1 SNPs rs4964879 and rs9481 reported in this study are located in intron and 3'UTR regions, respectively. Although introns are untranslated regions in mRNAs, mutations in introns may affect the binding of transcription factors and change the splicing modes or transcription of the $U L K 1$ gene, ultimately altering the sequence of amino acids (Kawasaki et al. 2018). The 3'UTR plays an important role in mRNA transport, stability and posttranscriptional regulation. Trans-acting factors or microRNAs bind to cisacting elements in the 3'UTR of the target transcript and regulate protein synthesis by affecting transcription factors. Sequence variations in mRNA introns or 3'UTR regions in ULK1 may cause abnormal expression of the gene (Zhang et al. 2019). Considering the role of ULK1 in the autophagy pathway, we speculate that $U L K 1$ (rs4964879 and rs9481) variations may lead to abnormal expression of ULK1 and then initiate the autophagy response, eventually increasing the susceptibility to MPA.

In the present study, another autophagy-related gene, PIK3CA (rs1607237, C>T), showed significant differences in the allele frequency and genotypic distribution between the patients with MPA and the healthy controls. A subject with at least one $\mathrm{T}$ allele has approximately half the risk for MPA compared with a subject with a $\mathrm{CC}$ genotype (TT+CT vs. CC: OR $0.56,95 \% \mathrm{CI}$ : $0.37-0.83)$. Increasing findings confirm that polymorphisms in the PI3K/AKT signaling pathway are related to the regulation of cell proliferation, survival and death. Similar to the results of our study, a case-control study conducted by Xing et al. found that the PIK3CA polymorphism is a defense factor against follicular thyroid cancer (Xing et al. 2012). PIK3CA rs1607237 is also significantly associated with a small decrease in breast cancer risk (Stevens et al. 2011). SNP rs 1607237 is in the intron of PIK3CA gene. Although no published literature has reported the feature of PIK3CA rs1607237, given the location of this SNP, we speculate that SNPs may affect the transcription of the PIK3CA gene by interrupting the process of translation and splicing. The PIK3CA mutation increases the expression of the p110 $\alpha$ catalytic subunit of PI3K and then activates AKT through the PI3K/AKT signaling pathway. As mentioned above, the PI3K/AKT pathway positively regulates the mTOR/ULK1 pathway, and the activation of AKT may decrease the autophagy response. However, further research will be needed to provide strong evidence for this speculation.

This study has several limitations, which should be mentioned. First, the number of participants was relatively small because of the low incidence rate of MPA, especially for subpopulations after stratified analysis, which may provide insufficient evidence to provide definitive conclusions. Second, some follow-up information, such as the curative effect of glucocorticoids and immunosuppressants, renal survival rate, relapse rate, and mortality, was lacking. Third, we did not perform studies to explore the molecular mechanisms to verify the association between gene polymorphisms reported in this study and MPA.

\section{Conclusions}

Peer] reviewing PDF | (2021:06:62693:2:0:NEW 30 Sep 2021) 
The present study indicated that the polymorphisms observed in ULKI (rs4964879 and rs9481) and PIK3CA (rs1607237) were significantly associated with MPA risk in the Guangxi population. However, the molecular mechanisms are still unclear, and studies designed with larger samples and basic research are needed to confirm our conclusions and explore the mechanisms.

\section{Acknowledgments}

We thank our colleagues in the Department of Nephrology, the Second Affiliated Hospital of Guangxi Medical University and the Experimental Center of Guangxi Medical University for their administrative and academic support. We also thank all participants enrolled in this study.

\section{References}

Al-Hussain T, Hussein MH, Conca W, Al Mana H, and Akhtar M. 2017. Pathophysiology of ANCAassociated Vasculitis. Adv Anat Pathol 24:226-234. 10.1097/pap.0000000000000154

Chan EYW, Kir S, and Tooze SA. 2007. siRNA Screening of the Kinome Identifies ULK1 as a Multidomain Modulator of Autophagy. Journal of Biological Chemistry 282:25464-25474. 10.1074/jbc.M703663200

Chang DY, Li ZY, Chen M, and Zhao MH. 2019. Myeloperoxidase-ANCA-positive granulomatosis with polyangiitis is a distinct subset of ANCA-associated vasculitis: A retrospective analysis of 455 patients from a single center in China. Semin Arthritis Rheum 48:701-706. 10.1016/j.semarthrit.2018.05.003

Cheong H, Lindsten T, Wu J, Lu C, and Thompson CB. 2011. Ammonia-induced autophagy is independent of ULK1/ULK2 kinases. Proc Natl Acad Sci U S A 108:11121-11126. 10.1073/pnas. 1107969108

Geetha D, and Jefferson JA. 2020. ANCA-Associated Vasculitis: Core Curriculum 2020. Am J Kidney Dis 75:124-137. 10.1053/j.ajkd.2019.04.031

Hervier B, Hamidou M, Haroche J, Durant C, Mathian A, and Amoura Z. 2012. Systemic lupus erythematosus associated with ANCA-associated vasculitis: an overlapping syndrome? Rheumatol Int 32:3285-3290. 10.1007/s00296-011-2055-z

Horne DJ, Graustein AD, Shah JA, Peterson G, Savlov M, Steele S, Narita M, and Hawn TR. 2016. Human ULK1 Variation and Susceptibility to Mycobacterium tuberculosis Infection. J Infect Dis 214:1260-1267. 10.1093/infdis/jiw347

Jennette JC, Falk RJ, Bacon PA, Basu N, Cid MC, Ferrario F, Flores-Suarez LF, Gross WL, Guillevin L, Hagen EC, Hoffman GS, Jayne DR, Kallenberg CG, Lamprecht P, Langford CA, Luqmani RA, Mahr AD, Matteson EL, Merkel PA, Ozen S, Pusey CD, Rasmussen N, Rees AJ, Scott DG, Specks U, Stone JH, Takahashi K, and Watts RA. 2013. 2012 revised International Chapel Hill Consensus Conference Nomenclature of Vasculitides. Arthritis and rheumatism 65:1-11. $10.1002 /$ art. 37715

Kawasaki A, Yamashita K, Hirano F, Sada KE, Tsukui D, Kondo Y, Kimura Y, Asako K, Kobayashi S, Yamada H, Furukawa H, Nagasaka K, Sugihara T, Yamagata K, Sumida T, Tohma S, Kono H, Ozaki S, Matsuo S, Hashimoto H, Makino H, Arimura Y, Harigai M, and Tsuchiya N. 2018. Association of ETS1 polymorphism with granulomatosis with polyangiitis and proteinase 3-antineutrophil cytoplasmic antibody positive vasculitis in a Japanese population. J Hum Genet 63:5562. $10.1038 / \mathrm{s} 10038-017-0362-2$

Lin MG, and Hurley JH. 2016. Structure and function of the ULK1 complex in autophagy. Curr Opin Cell Biol 39:61-68. 10.1016/j.ceb.2016.02.010

López P, Alonso-Pérez E, Rodríguez-Carrio J, and Suárez A. 2013. Influence of Atg5 mutation in SLE depends on functional IL-10 genotype. PLoS One 8:e78756. 10.1371/journal.pone.0078756

Lyons PA, Rayner TF, Trivedi S, Holle JU, Watts RA, Jayne DR, Baslund B, Brenchley P, Bruchfeld A, 
345

346

347

348

349

350

351

352

353

354

355

356

357

358

359

360

361

362

363

364

365

366

367

368

369

370

371

372

373

374

375

376

377

378

379

380

381

382

383

384

385

386

387

388

389

390

391

392

393

394

395

Chaudhry AN, Cohen Tervaert JW, Deloukas P, Feighery C, Gross WL, Guillevin L, Gunnarsson I, Harper L, Hruskova Z, Little MA, Martorana D, Neumann T, Ohlsson S, Padmanabhan S, Pusey CD, Salama AD, Sanders JS, Savage CO, Segelmark M, Stegeman CA, Tesar V, Vaglio A, Wieczorek S, Wilde B, Zwerina J, Rees AJ, Clayton DG, and Smith KG. 2012. Genetically distinct subsets within ANCA-associated vasculitis. $N$ Engl $J$ Med 367:214-223. 10.1056/NEJMoa1108735

Merkel PA, Xie G, Monach PA, Ji X, Ciavatta DJ, Byun J, Pinder BD, Zhao A, Zhang J, Tadesse Y, Qian D, Weirauch M, Nair R, Tsoi A, Pagnoux C, Carette S, Chung S, Cuthbertson D, Davis JC, Jr., Dellaripa PF, Forbess L, Gewurz-Singer O, Hoffman GS, Khalidi N, Koening C, Langford CA, Mahr AD, McAlear C, Moreland L, Seo EP, Specks U, Spiera RF, Sreih A, St Clair EW, Stone JH, Ytterberg SR, Elder JT, Qu J, Ochi T, Hirano N, Edberg JC, Falk RJ, Amos CI, Siminovitch KA, and Vasculitis Clinical Research C. 2017. Identification of Functional and Expression Polymorphisms Associated With Risk for Antineutrophil Cytoplasmic Autoantibody-Associated Vasculitis. Arthritis Rheumatol 69:1054-1066. 10.1002/art.40034

Mohamed DZ, El-Sisi AEE, Sokar SS, Shebl AM, and Abu-Risha SE. 2021. Targeting autophagy to modulate hepatic ischemia/reperfusion injury: A comparative study between octreotide and melatonin as autophagy modulators through AMPK/PI3K/AKT/mTOR/ULK1 and Keap1/Nrf2 signaling pathways in rats. Eur J Pharmacol 897:173920. 10.1016/j.ejphar.2021.173920

Morgan AR, Lam WJ, Han DY, Fraser AG, and Ferguson LR. 2012. Association Analysis of ULK1 with Crohn's Disease in a New Zealand Population. Gastroenterol Res Pract 2012:715309. 10.1155/2012/715309

Qu L, Li G, Xia D, Hongdu B, Xu C, Lin X, and Chen Y. 2016. PRKCI negatively regulates autophagy via PIK3CA/AKT-MTOR signaling. Biochemical and Biophysical Research Communications 470:306-312. 10.1016/j.bbrc.2016.01.059

Ramponi G, Folci M, De Santis M, Damoiseaux J, Selmi C, and Brunetta E. 2021. The biology, pathogenetic role, clinical implications, and open issues of serum anti-neutrophil cytoplasmic antibodies. Autoimmun Rev 20:102759. 10.1016/j.autrev.2021.102759

Saravani M, Shahraki-Ghadimi H, Maruei-Milan R, Mehrabani M, Mirzamohammadi S, and Nematollahi MH. 2020. Effects of the mTOR and AKT genes polymorphisms on systemic lupus erythematosus risk. Mol Biol Rep 47:3551-3556. 10.1007/s11033-020-05446-y

Sha LL, Wang H, Wang C, Peng HY, Chen M, and Zhao MH. 2016. Autophagy is induced by antineutrophil cytoplasmic Abs and promotes neutrophil extracellular traps formation. Innate Immun 22:658-665. 10.1177/1753425916668981

Shi YY, and He L. 2005. SHEsis, a powerful software platform for analyses of linkage disequilibrium, haplotype construction, and genetic association at polymorphism loci. Cell Res 15:97-98. $10.1038 /$ sj.cr.7290272

Skendros P, Mitroulis I, and Ritis K. 2018. Autophagy in Neutrophils: From Granulopoiesis to Neutrophil Extracellular Traps. Front Cell Dev Biol 6:109. 10.3389/fcell.2018.00109

Stevens KN, Garcia-Closas M, Fredericksen Z, Kosel M, Pankratz VS, Hopper JL, Dite GS, Apicella C, Southey MC, Schmidt MK, Broeks A, Van 't Veer LJ, Tollenaar RA, Fasching PA, Beckmann MW, Hein A, Ekici AB, Johnson N, Peto J, dos Santos Silva I, Gibson L, Sawyer E, Tomlinson I, Kerin MJ, Chanock S, Lissowska J, Hunter DJ, Hoover RN, Thomas GD, Milne RL, Arias Perez JI, Gonzalez-Neira A, Benitez J, Burwinkel B, Meindl A, Schmutzler RK, Bartrar CR, Hamann U, Ko YD, Bruning T, Chang-Claude J, Hein R, Wang-Gohrke S, Dork T, Schurmann P, Bremer M, Hillemanns P, Bogdanova N, Zalutsky JV, Rogov YI, Antonenkova N, Lindblom A, Margolin S, Mannermaa A, Kataja V, Kosma VM, Hartikainen J, Chenevix-Trench G, Chen X, Peterlongo P, Bonanni B, Bernard L, Manoukian S, Wang X, Cerhan J, Vachon CM, Olson J, Giles GG, Baglietto L, McLean CA, Severi G, John EM, Miron A, Winqvist R, Pylkas K, Jukkola-Vuorinen A, Grip M, Andrulis I, Knight JA, Glendon G, Mulligan AM, Cox A, Brock IW, Elliott G, Cross SS, Pharoah PP, Dunning AM, Pooley KA, Humphreys MK, Wang J, Kang D, Yoo KY, Noh DY, Sangrajrang S, Gabrieau V, Brennan P, McKay J, Anton-Culver H, Ziogas A, Couch FJ, Easton

Peer] reviewing PDF | (2021:06:62693:2:0:NEW 30 Sep 2021) 
396

397

398

399

400

401

402

403

404

405

406

407

408

409

410

411

412

413

414

415

416

417

418

419

420

421

422

423

424

425

426

427

428
DF, Network G, kConFab I, and Australian Ovarian Cancer Study G. 2011. Evaluation of variation in the phosphoinositide-3-kinase catalytic subunit alpha oncogene and breast cancer risk. Br J Cancer 105:1934-1939. 10.1038/bjc.2011.448

Tang S, Zhang Y, Yin SW, Gao XJ, Shi WW, Wang Y, Huang X, Wang L, Zou LY, Zhao JH, Huang YJ, Shan LY, Gounni AS, Wu YZ, and Zhang JB. 2015. Neutrophil extracellular trap formation is associated with autophagy-related signalling in ANCA-associated vasculitis. Clinical and experimental immunology 180:408-418. 10.1111/cei.12589

Wu DJ, and Adamopoulos IE. 2017. Autophagy and autoimmunity. Clinical Immunology 176:55-62. 10.1016/j.clim.2017.01.007

Xie G, Roshandel D, Sherva R, Monach PA, Lu EY, Kung T, Carrington K, Zhang SS, Pulit SL, Ripke S, Carette S, Dellaripa PF, Edberg JC, Hoffman GS, Khalidi N, Langford CA, Mahr AD, St Clair EW, Seo P, Specks U, Spiera RF, Stone JH, Ytterberg SR, Raychaudhuri S, de Bakker PIW, Farrer LA, Amos CI, Merkel PA, and Siminovitch KA. 2013. Association of granulomatosis with polyangiitis (Wegener's) with HLA-DPB $1 * 04$ and SEMA6A gene variants: evidence from genome-wide analysis. Arthritis and rheumatism 65:2457-2468. 10.1002/art.38036

Xing JC, Tufano RP, Murugan AK, Liu D, Wand G, Ladenson PW, Xing M, and Trink B. 2012. Single nucleotide polymorphism rs17849071 G/T in the PIK3CA gene is inversely associated with follicular thyroid cancer and PIK3CA amplification. PLoS One 7:e49192. 10.1371/journal.pone.0049192

Ye X, Zhou XJ, and Zhang H. 2019. Autophagy in Immune-Related Renal Disease. J Immunol Res 2019:5071687. 10.1155/2019/5071687

Zhang H, and Zhou L. 2019. Single nucleotide polymorphism of PIK3CA and its interaction with the environment are risk factors for Chinese Han ovarian cancer. Pathol Res Pract 215:152520. 10.1016/j.prp.2019.152520

Zhang RR, Liang L, Chen WW, Wen C, Wan BS, Luo LL, Zhao YL, Chen J, and Yue J. 2019. ULK1 polymorphisms confer susceptibility to pulmonary tuberculosis in a Chinese population. Int $J$ Tuberc Lung Dis 23:265-271. 10.5588/ijtld.18.0174

Zhang X, Han R, Wang M, Li X, Yang X, Xia Q, Liu R, Yuan Y, Hu X, Chen M, Jiang G, Ma Y, Yang J, $\mathrm{Xu} \mathrm{S,} \mathrm{Xu} \mathrm{J,} \mathrm{Shuai} \mathrm{Z,} \mathrm{and} \mathrm{Pan} \mathrm{F.} \mathrm{2017.} \mathrm{Association} \mathrm{between} \mathrm{the} \mathrm{autophagy-related} \mathrm{geneULK1} \mathrm{and}$ ankylosing spondylitis susceptibility in the Chinese Han population: a case-control study. Postgraduate Medical Journal 93:752-757. 10.1136/postgradmedj-2017-134964 
Figure 1

Graphical representation of the SNP locations and LD structure

A) LD plots containing 6 SNPs from ULK1; B) LD plots containing 2 SNPs from PIK3CA
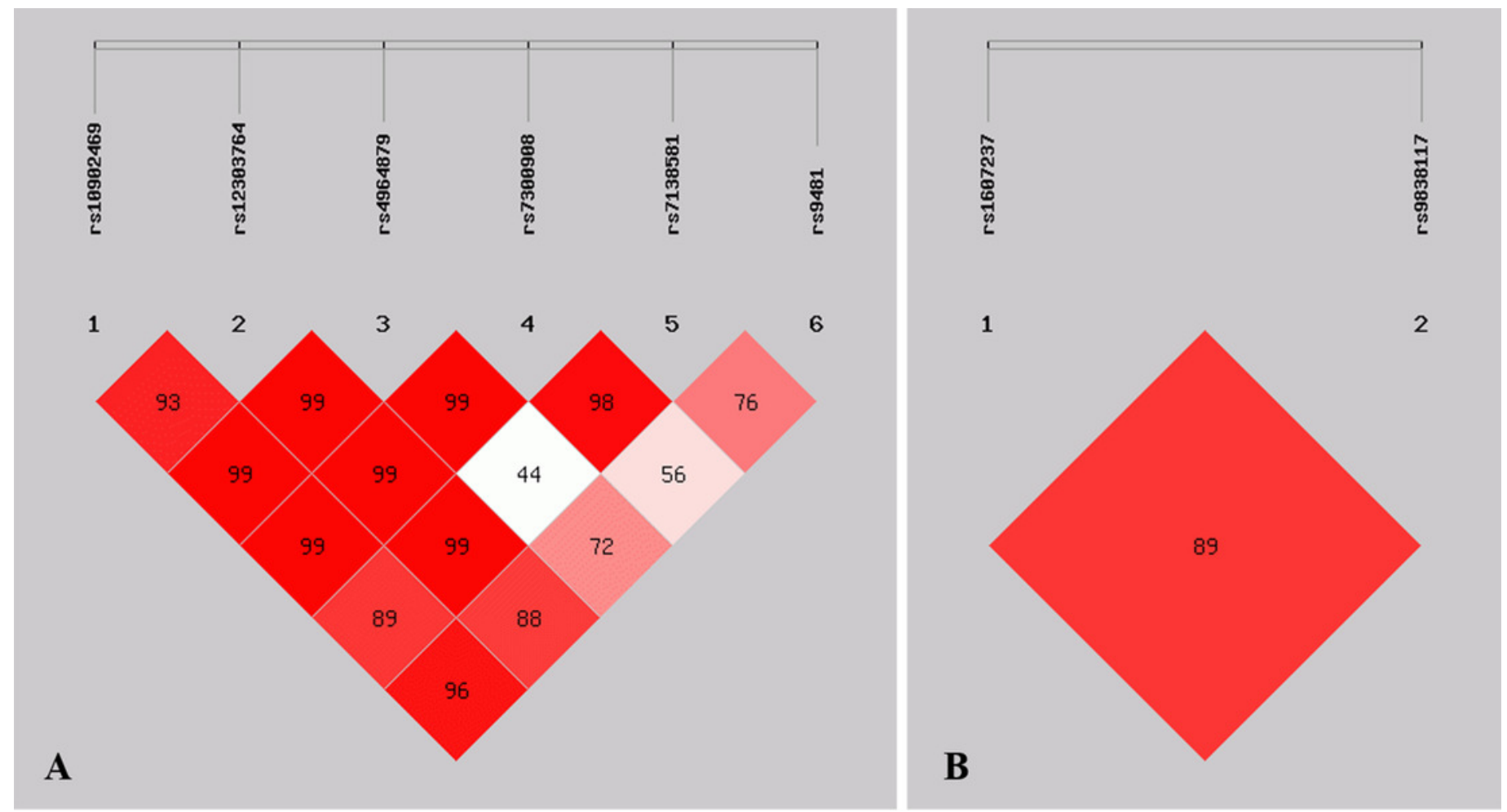
Figure 2

Distribution of high-risk and low risk genotypes in the best two-locus model

Dark gray and light gray boxed presented the high- and low- risk factor combinations, respectively. Left bars within each box represented case with positive score, right bars represented negative score. The higher the positive score, the greater the combination risk. GA in rs4964879 and CC in rs 1607237 showed the most risk combinations. 


\section{rs4964879}

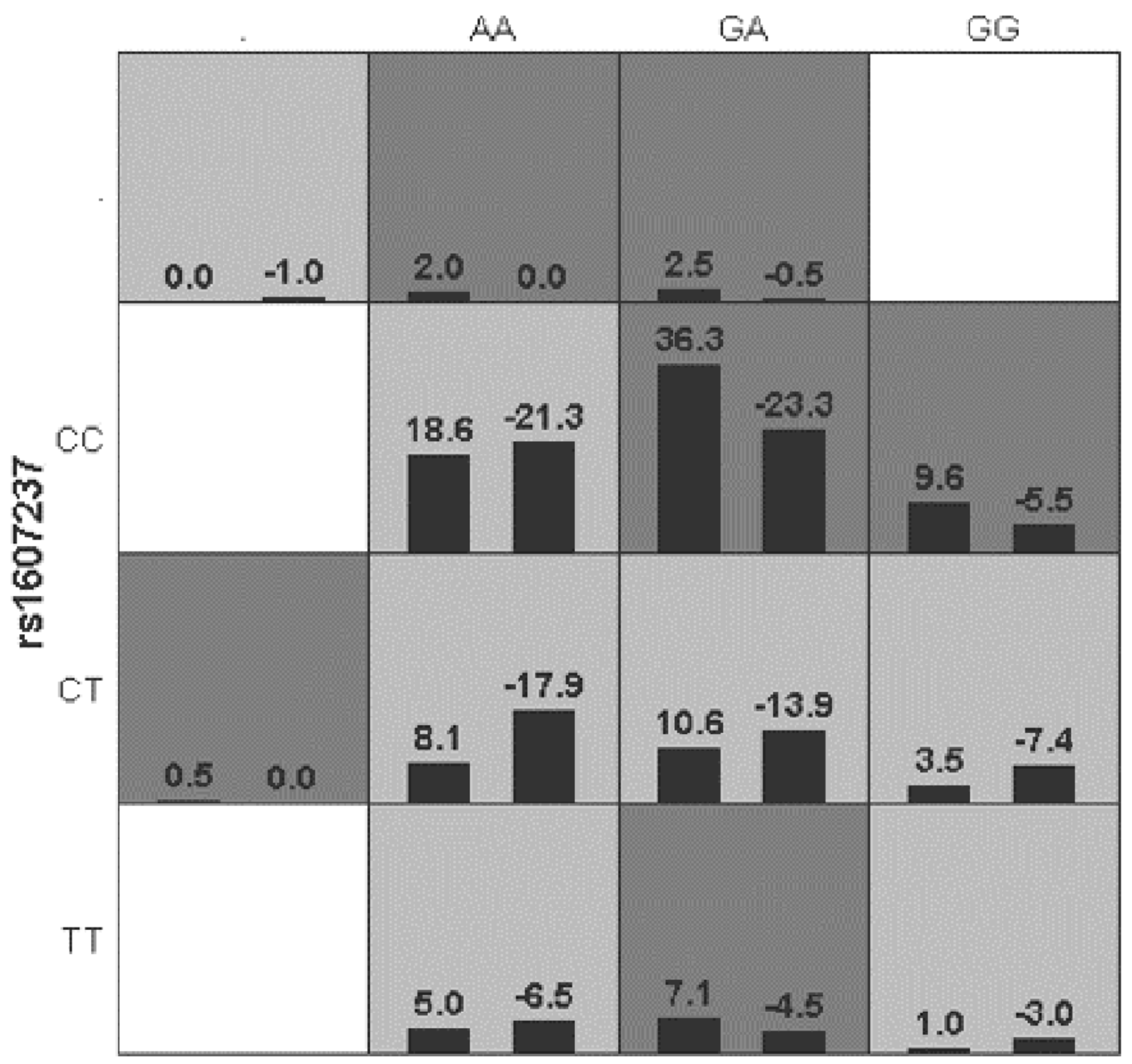


Table $\mathbf{1}$ (on next page)

Demographic characteristics of the study participants 
1 Table 1 Demographic characteristic of the study participants.

\begin{tabular}{lcc}
\hline Characteristic & MPA group (n=208) & control group (n=211) \\
\hline Age (years) & $54.6 \pm 14.9$ & $51.2 \pm 12.6$ \\
$\quad<\mathbf{6 0}$ & $114(54.8)$ & $160(75.8)$ \\
$\geqslant \mathbf{6 0}$ & $94(45.2)$ & $51(24.2)$ \\
Gender (M/F) & $78 / 130$ & $83 / 128$ \\
Ethnicity (Han/Zhuang) & $131 / 75$ & $155 / 56$ \\
BVAS (mean \pm SD) & $16.8 \pm 4.43$ & - \\
Renal pathologic classification & & \\
(Renal biopsy, n=89) & & \\
$\quad$ Focal & $36(40.4 \%)$ & \\
$\quad$ Crescentic & $9(10.1 \%)$ & \\
$\quad$ Mixed & $20(22.5 \%)$ & \\
$\quad$ Sclerotic & $24(27.0 \%)$ & \\
$\quad$ Renal tubulointerstitial & & \\
injury (Renal biopsy, $\mathbf{n}=\mathbf{8 9})$ & & \\
$\quad$ Score 1 & & \\
Score 2 & & \\
Score 3 & $41(41.6 \%)$ & \\
\hline
\end{tabular}




\section{Table 2 (on next page)}

Basic information about SNPs in ULK1 and PIK3CA and association with risk of AAV 
1 Table 2 Basic information about SNPs in ULK1 and PIK3CA and their association with the risk of AAV

2

\begin{tabular}{l|l|l|l|ll|l|l}
\hline \multirow{2}{*}{ Gene } & \multirow{2}{*}{ SNP ID } & \multirow{2}{*}{ Location } & \multirow{2}{*}{ Alleles } & \multicolumn{2}{|c|}{ MAF } & p for allele & $\boldsymbol{p}$ for \\
\cline { 5 - 8 } & & & & Case & Control & frequencies & genotypes \\
\hline \multirow{4}{*}{$U L K 1$} & rs10902469 & $12: 132378133$ & $\mathrm{G}>\mathrm{C}$ & 0.079 & 0.069 & 0.571 & 0.832 \\
\cline { 2 - 8 } & $\mathrm{rs} 12303764$ & $12: 132399065$ & $\mathrm{~T}>\mathrm{G}$ & 0.200 & 0.185 & 0.566 & 0.678 \\
\cline { 2 - 8 } & $\mathrm{rs} 4964879$ & $12: 132400309$ & $\mathrm{~A}>\mathrm{G}$ & 0.406 & 0.356 & 0.143 & $\mathbf{0 . 0 1 9}$ \\
\cline { 2 - 8 } & $\mathrm{rs} 7300908$ & $12: 132405421$ & $\mathrm{C}>\mathrm{T}$ & 0.099 & 0.090 & 0.673 & 0.897 \\
\cline { 2 - 8 } & $\mathrm{rs} 7138581$ & $12: 132406666$ & $\mathrm{G}>\mathrm{C}$ & 0.174 & 0.167 & 0.781 & 0.853 \\
\cline { 2 - 8 } & $\mathrm{rs} 9481$ & $12: 132407089$ & $\mathrm{~A}>\mathrm{G}$ & 0.442 & 0.378 & 0.060 & 0.070 \\
\hline \multirow{3}{*}{$P I K 3 C A$} & $\mathrm{rs} 1607237$ & $3: 178950297$ & $\mathrm{C}>\mathrm{T}$ & 0.240 & 0.325 & $\mathbf{0 . 0 1 1}$ & $\mathbf{0 . 0 0 2}$ \\
\cline { 2 - 8 } & $\mathrm{rs} 9838117$ & $3: 178952507$ & $\mathrm{G}>\mathrm{T}$ & 0.168 & 0.165 & 0.901 & 0.765 \\
\hline
\end{tabular}

3 


\section{Table 3 (on next page)}

The genotype frequencies of the studied ULKI and PIK3CA gene SNPs in the cases and the healthy controls 
1 Table 3 The genotype frequencies of the studied ULK1 and PIK3CA gene SNPs in the cases and the healthy controls

\begin{tabular}{|c|c|c|c|c|c|c|}
\hline SNP ID & Model & Genotype & $\begin{array}{l}\text { Control } \\
\text { n (\%) }\end{array}$ & $\begin{array}{l}\text { AVV } \\
\text { n (\%) }\end{array}$ & OR (95\% CI) & $p$ \\
\hline \multirow{4}{*}{$\begin{array}{l}\text { ULK1 } \\
\text { rs4964879 }\end{array}$} & Codominant & $\begin{array}{l}\text { AA } \\
\text { GA } \\
\text { GG }\end{array}$ & $\begin{array}{l}92(44) \\
85(40.7) \\
32(15.3)\end{array}$ & $\begin{array}{l}67(32.4) \\
112(54.1) \\
28(13.5)\end{array}$ & $\begin{array}{l}1.00 \\
\mathbf{1 . 7 6}(\mathbf{1 . 1 5 - 2 . 7 0 )} \\
1.19(0.65-2.16)\end{array}$ & 0.03 \\
\hline & Dominant & $\begin{array}{l}\mathrm{AA} \\
\mathrm{GA}+\mathrm{GG}\end{array}$ & $\begin{array}{l}92(44) \\
117(56) \\
\end{array}$ & $\begin{array}{l}68(31.9) \\
145(68.1) \\
\end{array}$ & $\begin{array}{l}1.00 \\
\mathbf{1 . 6 0}(\mathbf{1 . 0 7 - 2 . 4 0 )}\end{array}$ & 0.022 \\
\hline & Recessive & $\begin{array}{l}\mathrm{AA}+\mathrm{GA} \\
\mathrm{GG}\end{array}$ & $\begin{array}{l}177(84.7) \\
32(15.3) \\
\end{array}$ & $\begin{array}{l}184(86.4) \\
29(13.6) \\
\end{array}$ & $\begin{array}{l}1.00 \\
0.87(0.50-1.51)\end{array}$ & 0.61 \\
\hline & Overdominant & $\begin{array}{l}\mathrm{AA}+\mathrm{GG} \\
\mathrm{GA}\end{array}$ & $\begin{array}{l}124(59.3) \\
85(40.7) \\
\end{array}$ & $\begin{array}{l}97(45.5) \\
116(54.5) \\
\end{array}$ & $\begin{array}{l}1.00 \\
\mathbf{1 . 6 8}(\mathbf{1 . 1 3 - 2 . 4 9 )}\end{array}$ & 0.0096 \\
\hline \multirow{4}{*}{$\begin{array}{l}U L K 1 \\
\text { rs } 9481\end{array}$} & Codominant & $\begin{array}{l}\text { AA } \\
\text { AG } \\
\text { GG }\end{array}$ & $\begin{array}{l}81(38.8) \\
98(46.9) \\
30(14.3) \\
\end{array}$ & $\begin{array}{l}73(34.3) \\
90(42.2) \\
50(23.5)\end{array}$ & $\begin{array}{l}1.00 \\
1.00(0.65-1.54) \\
1.76(1.01-3.09) \\
\end{array}$ & 0.086 \\
\hline & Dominant & $\begin{array}{l}\mathrm{AA} \\
\mathrm{AG} / \mathrm{GG}\end{array}$ & $\begin{array}{l}81(38.8) \\
128(61.2)\end{array}$ & $\begin{array}{l}73(34.3) \\
140(65.7)\end{array}$ & $\begin{array}{l}1.00 \\
1.18(0.79-1.76)\end{array}$ & 0.36 \\
\hline & Recessive & $\begin{array}{l}\mathrm{AA} / \mathrm{AG} \\
\mathrm{GG}\end{array}$ & $\begin{array}{l}179(85.7) \\
30(14.3)\end{array}$ & $\begin{array}{l}163(76.5) \\
50(23.5) \\
\end{array}$ & $\begin{array}{l}1.00 \\
\mathbf{1 . 7 7}(\mathbf{1 . 0 6 - 2 . 9 4 )}\end{array}$ & 0.027 \\
\hline & Overdominant & $\begin{array}{l}\mathrm{AA} / \mathrm{GG} \\
\mathrm{AG}\end{array}$ & $\begin{array}{l}111(53.1) \\
98(46.9)\end{array}$ & $\begin{array}{l}123(57.8) \\
90(42.2)\end{array}$ & $\begin{array}{l}1.00 \\
0.83(0.56-1.22)\end{array}$ & 0.34 \\
\hline \multirow{4}{*}{$\begin{array}{l}\text { PIK3CA } \\
\text { rs1607237 }\end{array}$} & Codominant & $\begin{array}{l}\mathrm{CC} \\
\mathrm{CT} \\
\mathrm{TT} \\
\end{array}$ & $\begin{array}{l}101(48.6) \\
79(38) \\
28(13.5)\end{array}$ & $\begin{array}{l}138(64.3) \\
45(22.6) \\
26(13.1) \\
\end{array}$ & $\begin{array}{l}1.00 \\
\mathbf{0 . 4 7}(\mathbf{0 . 3 0 - 0 . 7 3 )} \\
0.78(0.43-1.42) \\
\end{array}$ & 0.0039 \\
\hline & Dominant & $\begin{array}{l}\mathrm{CC} \\
\mathrm{CT} / \mathrm{TT} \\
\end{array}$ & $\begin{array}{l}101(48.6) \\
107(51.4)\end{array}$ & $\begin{array}{l}128(64.3) \\
71(35.7)\end{array}$ & $\begin{array}{l}1.00 \\
\mathbf{0 . 5 5}(\mathbf{0 . 3 7 - 0 . 8 2 )}\end{array}$ & 0.0031 \\
\hline & Recessive & $\begin{array}{l}\mathrm{CC} / \mathrm{CT} \\
\mathrm{TT} \\
\end{array}$ & $\begin{array}{l}180(86.5) \\
28(13.5) \\
\end{array}$ & $\begin{array}{l}173(86.9) \\
26(13.1) \\
\end{array}$ & $\begin{array}{l}1.00 \\
1.01(0.57-1.81)\end{array}$ & 0.97 \\
\hline & Overdominant & $\begin{array}{l}\mathrm{CC} / \mathrm{TT} \\
\mathrm{CT}\end{array}$ & $\begin{array}{l}129(62) \\
79(38)\end{array}$ & $\begin{array}{l}154(77.4) \\
45(22.6)\end{array}$ & $\begin{array}{l}1.00 \\
0.49(0.32-0.76)\end{array}$ & 0.0013 \\
\hline
\end{tabular}


Table 4 (on next page)

The correlation between the haplotypes of ULK1 and PIK3CA gene SNPs and the AAV susceptibility 
1 Table 4 The correlation between the haplotypes of $U L K 1$ and $P I K 3 C A$ gene SNPs and the AAV susceptibility 2

\begin{tabular}{|c|c|c|c|c|c|}
\hline Gene & Haplotype & $\operatorname{AAV}(n=214)$ & $\begin{array}{l}\text { Control } \\
(n=211)\end{array}$ & OR $(95 \%$ CI $)$ & $p$ \\
\hline \multirow{6}{*}{$U L K 1$} & C-T-A-C-C-G & $27.6(6.7 \%)$ & $27.1(6.5 \%)$ & $1.039(0.599 \sim 1.799)$ & 0.893 \\
\hline & G-G-G-G-G & $80.8(19.5 \%)$ & $67.0(16 \%)$ & $1.285(0.897 \sim 1.841)$ & 0.171 \\
\hline & G-T-A-C-G-A & $203.7(49.2 \%)$ & $234.5(56.1 \%)$ & $0.749(0.563 \sim 0.997)$ & 0.047 \\
\hline & G-T-G-C-G-A & $13.9(3.4 \%)$ & $10.6(2.5 \%)$ & $1.343(0.596 \sim 3.024)$ & 0.475 \\
\hline & G-T-G-C-G-G & $26.8(6.5 \%)$ & $20.7(4.9 \%)$ & $1.340(0.741 \sim 2.422)$ & 0.331 \\
\hline & G-T-G-T-C-G & $30.8(7.4 \%)$ & $29.9(7.1 \%)$ & $1.054(0.624 \sim 1.780)$ & 0.844 \\
\hline \multirow{3}{*}{$P I K 3 C A$} & C-G & $291.5(73.3 \%)$ & $278.7(66.7 \%)$ & $1.427(1.050 \sim 1.939)$ & 0.023 \\
\hline & $\mathrm{T}-\mathrm{G}$ & $36.5(8.8 \%)$ & $68.3(16.3 \%)$ & $0.520(0.339 \sim 0.799)$ & 0.0025 \\
\hline & $\mathrm{T}-\mathrm{T}$ & $62.5(15.7 \%)$ & $66.7(16.0 \%)$ & $0.993(0.681 \sim 1.446]$ & 0.9688 \\
\hline
\end{tabular}

3 


\section{Table 5 (on next page)}

Distribution of ULK1 and PIK3CA polymorphisms in population of different ages and its association with risk of $A A V$ 


\begin{tabular}{|c|c|c|c|c|c|c|c|c|c|c|}
\hline \multirow{2}{*}{ SNP ID } & \multirow{2}{*}{ Model } & \multirow{2}{*}{$\begin{array}{l}\text { Geno } \\
\text { type }\end{array}$} & \multicolumn{3}{|c|}{ Age $<60$ years } & \multirow{2}{*}{$P$ value } & \multicolumn{3}{|c|}{ Age $\geqslant 60$ years } & \multirow{2}{*}{$p$ value } \\
\hline & & & Control & Case & OR (95\% CI) & & Control & Case & OR $(95 \%$ CI $)$ & \\
\hline \multirow{7}{*}{$\begin{array}{l}\text { ULK1 } \\
\text { rs4964879 }\end{array}$} & \multirow{2}{*}{ Codominant } & $\mathrm{AA}$ & $72(45 \%)$ & $39(34.2 \%)$ & 1.00 & & $20(40.8 \%)$ & $28(30.1 \%)$ & 1.00 & \\
\hline & & GG & $26(16.2 \%)$ & $17(14.9 \%)$ & $1.21(0.59-2.49)$ & & $6(12.2 \%)$ & $11(11.8 \%)$ & $1.37(0.43-4.35)$ & \\
\hline & \multirow{2}{*}{ Dominant } & $\mathrm{AA}$ & $72(45 \%)$ & $39(34.2 \%)$ & 1.00 & & $20(40.8 \%)$ & $28(20.1 \%)$ & 1.00 & \\
\hline & & GA/GG & $88(55 \%)$ & $75(65.8 \%)$ & $1.58(0.96-2.60)$ & 0.073 & $29(59.2 \%)$ & $65(69.9 \%)$ & $1.60(0.77-3.30)$ & 0.21 \\
\hline & Recessive & GG & $26(16.2 \%)$ & $17(14.9 \%)$ & $0.90(0.47-1.76)$ & 0.77 & $6(12.2 \%)$ & $11(11.8 \%)$ & $1.01(0.35-2.95)$ & 0.98 \\
\hline & \multirow{2}{*}{ Overdominant } & $\mathrm{AA} / \mathrm{GG}$ & $98(61.2 \%)$ & $56(49.1 \%)$ & 1.00 & & $26(53.1 \%)$ & $39(41.9 \%)$ & 1.00 & \\
\hline & & GA & $62(38.8 \%)$ & $58(50.9 \%)$ & $1.65(1.01-2.69)$ & 0.046 & $23(46.9 \%)$ & $54(58.1 \%)$ & $1.53(0.76-3.08)$ & 0.23 \\
\hline \multirow{5}{*}{$\begin{array}{l}U L K 1 \\
\text { rs } 9481\end{array}$} & \multirow[b]{2}{*}{ Codominant } & $\mathrm{AA}$ & $63(39.4 \%)$ & $40(35.1 \%)$ & 1.00 & & $18(36.7 \%)$ & $32(34.4 \%)$ & 1.00 & \\
\hline & & $\mathrm{AG}$ & $74(46.2 \%)$ & $47(41.2 \%)$ & $0.99(0.57-1.70)$ & 0.14 & $24(49 \%)$ & $40(43 \%)$ & $0.92(0.42-1.99)$ & 0.44 \\
\hline & Recessive & GG & $23(14.4 \%)$ & $27(23.7 \%)$ & $1.88(1.01-3.51)$ & 0.047 & $7(14.3 \%)$ & $21(22.6 \%)$ & $1.81(0.71-4.65)$ & 0.2 \\
\hline & \multirow{2}{*}{ Overdominant } & AA/GG & $86(53.8 \%)$ & $67(58.8 \%)$ & 1.00 & & $25(51 \%)$ & $53(57 \%)$ & 1.00 & \\
\hline & & AG & $74(46.2 \%)$ & $47(41.2 \%)$ & $0.81(0.49-1.32)$ & 0.39 & $24(49 \%)$ & $40(43 \%)$ & $0.77(0.38-1.54)$ & 0.45 \\
\hline \multirow{3}{*}{$\begin{array}{l}P I K 3 C A \\
\text { rs } 1607237\end{array}$} & \multirow{3}{*}{ Codominant } & $\mathrm{CC}$ & $76(47.8 \%)$ & $63(58.3 \%)$ & 1.00 & & $25(51 \%)$ & $65(71.4 \%)$ & 1.00 & \\
\hline & & $\mathrm{CT}$ & $58(36.5 \%)$ & $32(29.6 \%)$ & $0.67(0.39-1.15)$ & 0.23 & $21(42.9 \%)$ & $13(14.3 \%)$ & $0.23(0.10-0.53)$ & $6 e-04$ \\
\hline & & TT & $25(15.7 \%)$ & $13(12 \%)$ & $0.62(0.29-1.32)$ & & $3(6.1 \%)$ & $13(14.3 \%)$ & $1.70(0.44-6.51)$ & \\
\hline \multirow{4}{*}{$\begin{array}{l}\text { PIK3CA } \\
\text { rs } 1607237\end{array}$} & \multirow{2}{*}{ Dominant } & $\mathrm{CC}$ & $76(47.8 \%)$ & $63(58.3 \%)$ & 1.00 & & $25(51 \%)$ & $65(71.4 \%)$ & 1.00 & \\
\hline & & $\mathrm{CT} / \mathrm{TT}$ & $83(52.2 \%)$ & $45(41.7 \%)$ & $0.65(0.40-1.07)$ & 0.09 & $24(49 \%)$ & $26(28.6 \%)$ & $0.41(0.20-0.85)$ & 0.016 \\
\hline & \multirow{2}{*}{ Recessive } & $\mathrm{CC} / \mathrm{CT}$ & $134(84.3 \%)$ & $95(88 \%)$ & 1.00 & & $46(93.9 \%)$ & $78(85.7 \%)$ & 1.00 & \\
\hline & & TT & $25(15.7 \%)$ & $13(12 \%)$ & $0.73(0.35-1.49)$ & 0.38 & $3(6.1 \%)$ & $13(14.3 \%)$ & $2.61(0.70-9.71)$ & 0.12 \\
\hline
\end{tabular}




\begin{tabular}{l|l|l|l|l|l|l|l|l|l|l|l}
\hline \multirow{2}{*}{ Overdominant } & CC/TT & $101(63.5 \%)$ & $76(70.4 \%)$ & 1.00 & & $28(57.1 \%)$ & $78(85.7 \%)$ & 1.00 & \\
\cline { 3 - 12 } & & $\mathrm{CT}$ & $58(36.5 \%)$ & $32(29.6 \%)$ & $0.74(0.44-1.24)$ & 0.25 & $21(42.9 \%)$ & $13(14.3 \%)$ & $\mathbf{0 . 2 1}(\mathbf{0 . 0 9 - 0 . 4 9 )}$ & $\mathbf{2 e - 0 4}$ \\
\hline
\end{tabular}


Table 6(on next page)

Distribution of ULK1 and PIK3CA polymorphisms in population of different genders and its association with risk of AAV 


\begin{tabular}{|c|c|c|c|c|c|c|c|c|c|c|}
\hline \multirow{2}{*}{ SNP ID } & \multirow{2}{*}{ Model } & \multirow{2}{*}{$\begin{array}{l}\text { Geno- } \\
\text { type }\end{array}$} & \multicolumn{3}{|c|}{ Male } & \multirow{2}{*}{$p$ value } & \multicolumn{3}{|c|}{ female } & \multirow{2}{*}{$p$ value } \\
\hline & & & Control & case & OR (95\% CI) & & Control & Case & OR $(95 \%$ CI) & \\
\hline \multirow{7}{*}{$\begin{array}{l}U L K 1 \\
\text { rs4964879 }\end{array}$} & \multirow{2}{*}{ Codominant } & AA & $31(37.8 \%)$ & $23(29.1 \%)$ & 1.00 & & $61(48 \%)$ & $44(34.1 \%)$ & 1.00 & \\
\hline & & GG & $13(15.8 \%)$ & $10(12.7 \%)$ & $1.03(0.38-2.77)$ & & $19(15 \%)$ & $18(13.9 \%)$ & $1.28(0.60-2.73)$ & \\
\hline & \multirow{2}{*}{ Dominant } & AA & $31(37.8 \%)$ & $23(29.1 \%)$ & 1.00 & & $61(48 \%)$ & $44(34.1 \%)$ & 1.00 & \\
\hline & & GA/GG & $51(62.2 \%)$ & $56(70.9 \%)$ & $1.47(0.76-2.86)$ & 0.25 & $66(52 \%)$ & $85(65.9 \%)$ & $1.69(1.02-2.82)$ & 0.042 \\
\hline & Recessive & GG & $13(15.8 \%)$ & $10(12.7 \%)$ & $0.76(0.31-1.87)$ & 0.56 & $19(15 \%)$ & $18(13.9 \%)$ & $0.93(0.46-1.88)$ & 0.84 \\
\hline & \multirow{2}{*}{ Overdominant } & $\mathrm{AA} / \mathrm{GG}$ & $44(53.7 \%)$ & $33(41.8 \%)$ & 1.00 & & $80(63 \%)$ & $62(48.1 \%)$ & 1.00 & \\
\hline & & GA & $38(46.3 \%)$ & $46(58.2 \%)$ & $1.61(0.86-3.02)$ & 0.13 & $47(37 \%)$ & $67(51.9 \%)$ & $1.74(1.05-2.88)$ & 0.031 \\
\hline \multirow{5}{*}{$\begin{array}{l}U L K 1 \\
\text { rs9481 }\end{array}$} & \multirow[b]{2}{*}{ Codominant } & AA & $29(35.4 \%)$ & $28(35.4 \%)$ & 1.00 & & $52(40.9 \%)$ & $45(34.9 \%)$ & 1.00 & \\
\hline & & $\mathrm{AG}$ & $43(52.4 \%)$ & $36(45.6 \%)$ & $0.89(0.45-1.76)$ & 0.5 & $55(43.3 \%)$ & $51(39.5 \%)$ & $1.04(0.60-1.82)$ & 0.14 \\
\hline & Recessive & GG & $10(12.2 \%)$ & $15(19 \%)$ & $1.60(0.67-3.84)$ & 0.25 & $20(15.8 \%)$ & $33(25.6 \%)$ & $1.86(0.99-3.47)$ & 0.05 \\
\hline & \multirow{2}{*}{ Overdominant } & $\mathrm{AA} / \mathrm{GG}$ & $39(47.6 \%)$ & $43(54.4 \%)$ & 1.00 & & $72(56.7 \%)$ & $78(60.5 \%)$ & 1.00 & \\
\hline & & $\mathrm{AG}$ & $43(52.4 \%)$ & $36(45.6 \%)$ & $0.79(0.42-1.47)$ & 0.51 & $55(43.3 \%)$ & $51(39.5 \%)$ & $0.83(0.50-1.38)$ & 0.48 \\
\hline \multirow{3}{*}{$\begin{array}{l}P I K 3 C A \\
\text { rs1607237 }\end{array}$} & \multirow{3}{*}{ Codominant } & $\mathrm{CC}$ & $39(47.6 \%)$ & $51(66.2 \%)$ & 1.00 & & $62(49.2 \%)$ & $78(63.4 \%)$ & 1.00 & \\
\hline & & $\mathrm{CT}$ & $29(35.4 \%)$ & $15(19.5 \%)$ & $0.40(0.19-0.84)$ & 0.042 & $50(39.7 \%)$ & $30(24.4 \%)$ & $0.50(0.28-0.88)$ & 0.048 \\
\hline & & $\mathrm{TT}$ & $14(17.1 \%)$ & $11(14.3 \%)$ & $0.60(0.25-1.47)$ & & $14(11.1 \%)$ & $15(12.2 \%)$ & $0.93(0.41-2.11)$ & \\
\hline \multirow{4}{*}{$\begin{array}{l}\text { PIK3CA } \\
\text { rs } 1607237\end{array}$} & \multirow{2}{*}{ Dominant } & $\mathrm{CC}$ & $39(47.6 \%)$ & $51(66.2 \%)$ & 1.00 & & $62(49.2 \%)$ & $78(63.4 \%)$ & 1.00 & \\
\hline & & $\mathrm{CT} / \mathrm{TT}$ & $43(52.4 \%)$ & $26(33.8 \%)$ & $0.46(0.24-0.88)$ & 0.017 & $64(50.8 \%)$ & $45(36.6 \%)$ & $0.59(0.35-0.99)$ & 0.063 \\
\hline & \multirow{2}{*}{ Recessive } & $\mathrm{CC} / \mathrm{CT}$ & $68(82.9 \%)$ & $66(85.7 \%)$ & 1.00 & & $112(88.9 \%)$ & $108(87.8 \%)$ & 1.00 & \\
\hline & & $\mathrm{TT}$ & $14(17.1 \%)$ & $11(14.3 \%)$ & $0.81(0.34-1.91)$ & 0.63 & $14(11.1 \%)$ & $15(12.2 \%)$ & $1.21(0.55-2.66)$ & 0.64 \\
\hline
\end{tabular}




\begin{tabular}{|c|c|c|c|c|c|c|c|c|c|}
\hline \multirow{3}{*}{ Overdominant } & $\mathrm{CC} / \mathrm{TT}$ & $53(64.6 \%)$ & $62(80.5 \%)$ & 1.00 & & $76(60.3 \%)$ & $93(75.6 \%)$ & 1.00 & \\
\hline & $\mathrm{CT}$ & $29(35.4 \%)$ & $15(19.5 \%)$ & $0.44(0.21-0.91)$ & 0.024 & $50(39.7 \%)$ & $30(24.4 \%)$ & $0.50(0.29-0.88)$ & 0.014 \\
\hline & GA & $59(38.6 \%)$ & $68(52.3 \%)$ & $1.70(1.05-2.74)$ & 0.03 & $26(46.4 \%)$ & $42(5 \%)$ & $1.42(0.69-2.89)$ & 0.34 \\
\hline
\end{tabular}

3 


\section{Table 7 (on next page)}

Distribution of ULK1 and PIK3CA polymorphisms in population of different ethnicity and its association with risk of AAV 


\begin{tabular}{|c|c|c|c|c|c|c|c|c|c|c|}
\hline \multirow{2}{*}{ SNP ID } & \multirow{2}{*}{ Model } & \multirow{2}{*}{$\begin{array}{l}\text { Geno } \\
\text { type }\end{array}$} & \multicolumn{3}{|c|}{ Ethnicity $=$ Han } & \multirow{2}{*}{$p$ value } & \multicolumn{3}{|c|}{ Ethnicity = Zhuang } & \multirow{2}{*}{$p$ value } \\
\hline & & & Control & Case & OR (95\% CI) & & Control & Case & OR $(95 \%$ CI $)$ & \\
\hline \multirow{7}{*}{$\begin{array}{l}U L K 1 \\
\text { rs4964879 }\end{array}$} & \multirow{2}{*}{ Codominant } & $\mathrm{AA}$ & $73(47.7 \%)$ & $43(33.1 \%)$ & 1.00 & & $19(33.9 \%)$ & $24(32 \%)$ & 1.00 & \\
\hline & & GG & $21(13.7 \%)$ & $19(14.6 \%)$ & $1.48(0.71-3.07)$ & & $11(19.6 \%)$ & $9(12 \%)$ & $0.67(0.23-1.98)$ & \\
\hline & \multirow{2}{*}{ Dominant } & $\mathrm{AA}$ & $73(47.7 \%)$ & $43(33.1 \%)$ & 1.00 & & $19(33.9 \%)$ & $24(32 \%)$ & 1.00 & \\
\hline & & GA/GG & $80(52.3 \%)$ & $87(66.9 \%)$ & $1.78(1.09-2.90)$ & 0.02 & $37(66.1 \%)$ & $51(68 \%)$ & $1.07(0.50-2.28)$ & 0.86 \\
\hline & Recessive & $\mathrm{G} / \mathrm{G}$ & $21(13.7 \%)$ & $19(14.6 \%)$ & $1.06(0.54-2.07)$ & 0.87 & $11(19.6 \%)$ & $9(12 \%)$ & $0.58(0.22-1.55)$ & 0.28 \\
\hline & \multirow{2}{*}{ Overdominant } & AA/GG & $94(61.4 \%)$ & $62(47.7 \%)$ & 1.00 & & $30(53.6 \%)$ & $33(44 \%)$ & 1.00 & \\
\hline & & GA & $59(38.6 \%)$ & $68(52.3 \%)$ & $1.70(1.05-2.74)$ & 0.03 & $26(46.4 \%)$ & $42(5 \%)$ & $1.42(0.69-2.89)$ & 0.34 \\
\hline \multirow{5}{*}{$\begin{array}{l}U L K 1 \\
\text { rs } 9481\end{array}$} & \multirow[b]{2}{*}{ Codominant } & AA & $60(39.2 \%)$ & $47(36.1 \%)$ & 1.00 & & $21(37.5 \%)$ & $25(33.3 \%)$ & 1.00 & \\
\hline & & $\mathrm{AG}$ & $72(47.1 \%)$ & $54(41.5 \%)$ & $0.94(0.56-1.59)$ & 0.18 & $26(46.4 \%)$ & $32(42.7 \%)$ & $1.07(0.49-2.37)$ & 0.62 \\
\hline & Recessive & GG & $21(13.7 \%)$ & $31(23 \%)$ & $1.80(0.96-3.35)$ & 0.064 & $9(16.1 \%)$ & $18(24 \%)$ & $1.55(0.62-3.86)$ & 0.34 \\
\hline & \multirow{2}{*}{ Overdominant } & AA/GG & $81(52.9 \%)$ & $79(58.5 \%)$ & 1.00 & & $30(53.6 \%)$ & $43(57.3 \%)$ & 1.00 & \\
\hline & & AG & $72(47.1 \%)$ & $56(41.5 \%)$ & $0.79(0.49-1.27)$ & 0.33 & $26(46.4 \%)$ & $32(42.7 \%)$ & $0.91(0.44-1.87)$ & 0.8 \\
\hline \multirow{7}{*}{$\begin{array}{l}P I K 3 C A \\
\text { rs } 1607237\end{array}$} & \multirow{3}{*}{ Codominant } & $\mathrm{CC}$ & $76(49.7 \%)$ & $86(68.2 \%)$ & 1.00 & & $25(45.5 \%)$ & $40(56.3 \%)$ & 1.00 & \\
\hline & & $\mathrm{CT}$ & $59(38.6 \%)$ & $27(21.4 \%)$ & $0.42(0.24-0.73)$ & 0.0068 & $20(36.4 \%)$ & $18(25.4 \%)$ & $0.59(0.26-1.36)$ & 0.47 \\
\hline & & TT & $18(11.8 \%)$ & $13(10.3 \%)$ & $0.68(0.31-1.49)$ & & $10(18.2 \%)$ & $13(18.3 \%)$ & $0.81(0.30-2.18)$ & \\
\hline & \multirow{2}{*}{ Dominant } & $\mathrm{CC}$ & $76(49.7 \%)$ & $86(68.2 \%)$ & 1.00 & & $25(45.5 \%)$ & $40(56.3 \%)$ & 1.00 & \\
\hline & & $\mathrm{CT} / \mathrm{TT}$ & $77(50.3 \%)$ & $40(31.8 \%)$ & $0.48(0.29-0.78)$ & 0.0031 & $30(54.5 \%)$ & $31(43.7 \%)$ & $0.67(0.32-1.37)$ & 0.27 \\
\hline & \multirow{2}{*}{ Recessive } & $\mathrm{CC} / \mathrm{CT}$ & $135(88.2 \%)$ & $113(89.7 \%)$ & 1.00 & & $45(81.8 \%)$ & $58(81.7 \%)$ & 1.00 & \\
\hline & & TT & $18(11.8 \%)$ & $13(10.3 \%)$ & $0.91(0.43-1.97)$ & 0.82 & $10(18.2 \%)$ & $13(18.3 \%)$ & $0.97(0.38-2.51)$ & 0.96 \\
\hline
\end{tabular}




\begin{tabular}{l|l|l|l|l|l|l|l|l|l|l}
\hline \multirow{2}{*}{} & \multirow{2}{*}{ Overdominant } & CC/TT & $94(61.4 \%)$ & $99(78.6 \%)$ & 1.00 & & $35(63.6 \%)$ & $53(74.7 \%)$ & 1.00 & \\
\cline { 3 - 10 } & & $\mathrm{CT}$ & $59(38.6 \%)$ & $27(21.4 \%)$ & $\mathbf{0 . 4 4}(\mathbf{0 . 2 6 - 0 . 7 6 )}$ & $\mathbf{0 . 0 0 2 6}$ & $20(36.4 \%)$ & $18(25.4 \%)$ & $0.63(0.28-1.38)$ & 0.24 \\
\hline
\end{tabular}
3 